\title{
Android-Based Material for Sports Massage Learning
}

\author{
Boby Ardianzah Efendy ${ }^{1,}$, Achmad Sofyan Hanif ${ }^{2}$, Iman Sulaiman ${ }^{2}$, Muhsana El Cintami Lanos ${ }^{3}$ \\ ${ }^{1}$ IKIP Budi Utomo Malang, Indonesia \\ ${ }^{2}$ Sport Education, Program Pasca Sarjana, Universitas Negeri Jakarta, Indonesia \\ ${ }^{3}$ Sport Education, Universitas PGRI Palembang, Indonesia
}

Received July 26, 2021; Revised February 8, 2022; Accepted February 23, 2022

\section{Cite This Paper in the following Citation Styles}

(a): [1] Boby Ardianzah Efendy, Achmad Sofyan Hanif, Iman Sulaiman, Muhsana El Cintami Lanos, "Android-Based Material for Sports Massage Learning," International Journal of Human Movement and Sports Sciences, Vol. 10, No. 1, pp. 112 - 120, 2022. DOI: 10.13189/saj.2022.100116.

(b): Boby Ardianzah Efendy, Achmad Sofyan Hanif, Iman Sulaiman, Muhsana El Cintami Lanos (2022). Android-Based Material for Sports Massage Learning. International Journal of Human Movement and Sports Sciences, 10(1), 112 - 120. DOI: 10.13189/saj.2022.100116.

Copyright $\bigcirc 2022$ by authors, all rights reserved. Authors agree that this article remains permanently open access under the terms of the Creative Commons Attribution License 4.0 International License

\begin{abstract}
The Android application is a Linux-based operating system for cellular phones such as smartphones and tablet computers that can be designed as digital media to facilitate the need for teaching materials. The purpose of this study was to develop Android-based massage sports teaching materials for students in the Physical Education, Health, and Recreation Study Program. The research method was research and development with the Borg and Gall models. Data collection techniques included observation, interviews, questionnaires, tests, and documents. The participants involved were students, colleagues, and experts. The results of the study indicate that teaching materials for learning sports massage based on Android provide convenience in understanding the content of the material. Students can access materials easily at any time, both on-campus and off-campus. This application is called "MassageSmartClick," which can be accessed on mobile phones, and students can also study it in the print book that has been presented in the application. It has some menus, namely the splash menu, main menu, competency menu, material menu, illustration menu, evaluation menu, and information menu.
\end{abstract}

Keywords Android, Learning, Material, Massage, Sport

\section{Introduction}

Technological advances have been utilized for the implementation of teaching and learning in the 21 st century. In addition, students, as digital natives, can use various technological applications and educational processes must also direct students to have learning skills using technology and information media. They can apply these skills in everyday life. Therefore, educators must make adjustments to the current development of knowledge and technology so that educators can change traditional learning patterns into modern technology-based learning. It means that the educational process is carried out using technological products. Products of technological progress have broad benefits if teachers can use them well. A survey of 2,462 Advanced Placement (AP) and National Writing Project (NWP) teachers in America found digital technology as a tool that has helped teachers in teaching middle school and high school students in many ways. At the same time, the internet, mobile phones, and social media have brought new challenges to teachers [1]. Mobile learning is a new form of learning that takes advantage of the unique capabilities of mobile devices. The use of digital pictures, which were delivered via mobile device, proved to be surprisingly successful. Mobile learning is a new form of learning that takes advantage of the unique capabilities of mobile devices. The use of digital pictures, which were delivered via mobile device, proved to be surprisingly successful [2]. In colleges, the use of smartphones is still a hot trend. However, students do not yet have the readiness to use mobile as a learning medium. A study found that student acceptance of m-learning was quite good. More specifically, attitudes, subjective norms, and behavioural control positively influence their intention to adopt mobile 
learning. The results provide valuable rewards for increasing student acceptance of mobile learning. [3] But on the other hand, mobile learning is not a stable concept; therefore, its current interpretations need to be made explicit. Examples of current projects and practices show an affinity between mobile and game-based learning and can further illuminate what is distinctive and worthwhile about mobile learning [4].

Mobile Learning can provide the best support for learning in the dissemination and improvement of the quality of learning content. It means that teachers can innovate on learning content and students can access the content easily. In addition, mobile learning also facilitates the communication process during the learning process. Thus, mobile learning can be assumed as a learning medium that can be designed for synchronous and asynchronous methods. This medium can facilitate the teaching and learning needs of all subjects. One of them is physical education and sports. Several studies on the trend of using mobile learning in physical education articles that have been published in reputable journals show that the integration of new mobile technologies into physical education activities has increased from year to year. The application of mainstream mobile learning teaching strategies in physical education is also limited. Therefore, several research issues for mobile technology in physical education are recommended [5]. Other research shows that students who have low digital skills are often not ready to use mobile learning [6]. Therefore, one of the efforts to overcome this problem is to design mobile learning systems that are easy to use and simple. It may even be designed with a flexible application and can be operated with or without the internet.

One of the efforts to use technology in learning is to make the learning process more effective, efficient and interesting. The use of these technologies includes designing and developing learning materials in attractive packaging based on technology and information. Not only attractive in terms of appearance but also must be able to improve the quality of interaction in the student learning process. Therefore, the presentation of teaching materials must be harmonized with technological devices so that learning activities are easier and more interesting. One principle we use to design the materials is motivation. Motivation can be enhanced through challenge, curiosity, control, recognition, competition, and cooperation. This model helps inform our understanding of the motivating features of using mobile devices for learning and how mobile technologies can be used to enhance learners' motivation [7].

From the results of field observations at Institut Keguruan dan Ilmu Pendidikan Budi Utomo Malang, it is known that the Sports Massage course is one of the compulsory subjects and must be taught with the integration of technology devices. While the results of studies from various structures of the Physical Education,
Health and Recreation curriculum at other universities in Indonesia, such as Universitas Pendidikan Indonesia, Universitas Sebelas Maret Surakarta, Universitas Tadulako concluded that the sports massage course is also a compulsory subject and is presented with authentically open materials. With these findings, the ideal learning conditions in sports massage courses should be able to create a pleasant learning climate, attract attention, improve 21st-century learning competencies and innovation skills that involve technological advances through the presentation of relevant teaching materials. Therefore, teaching materials must be designed to develop the skills of today's century which include (a) critical thinking and problem solving, (b) communication and collaboration, (c) creativity and innovation.

However, this ideal condition has not been realized. Therefore, this research has an urgency for the Study Program in designing teaching materials in massage sports courses. The implementation of this research is supported by several reasons; 1) the use of technological devices has not been used in the provision of teaching materials, 2) students have technological devices to support online learning activities, 3) the need for authentic teaching materials can stimulate student learning experiences by utilizing technology tools that owned, 4) the demands of the learning process are relevant to the digital era, and 5) universities must be able to produce competent graduates in the 21 st century.

Many previous studies have examined the relationship between the development of teaching materials and technology. Educational institutions must develop digital models for all aspects of education delivery [8],[9]. Currently, the Internet of Things-based school sports intelligence system and artificial intelligence technology influence the management of school sports [8],[10],[11]. It means that schools have entered the digital era. In Sweden, adequate digital competence is in the spotlight due to Sweden's 2017 national strategy for digitizing the K-12 school system [12]. Various technological tools have been applied such as video, 3D animation, or website applications [13]. The multimedia has provided theoretical references in research related to sports teaching and learning [10], [14], [15]. However, some educators do not understand the application of these tools and ICT in learning [16], [17]. There is also cellular technology that has been utilized as multimedia in teaching and learning at all levels of education. Teachers have taken advantage of the combination of affordability of mobile technology and Apps that improve some aspects of learning practice [18]. Especially during the current covid-19 pandemic, mobile technology has made it easier to carry out learning [16], [18], [19].

Three constructs characterizing the pedagogy of mobile learning have emerged: authenticity, collaboration, and personalization. The pedagogical framework provides a spotlight to illuminate and examine mobile learning 
experiences, account still needs to be taken of learners' specific characteristics and needs, the environments in which the learning could potentially take place, and the preferences and characteristics of teachers, including their epistemological beliefs. Teacher roles and the learning task design are further crucial factors [20].

The last research concluded that technology has had a very big role in the teaching and learning process. However, in this study, the technology related to the development of massage sports teaching materials is an android application. It is a gap with previous research. This development focuses on designing android-based applications that are tailored to the context of the university and student backgrounds. Thus, the research is expected to be able to provide many benefits to the need for authentic teaching materials for sports teaching. Moreover, students at the University have technological devices that support learning activities. Teaching materials presented in the form of an android application help facilitate teaching and learning during the covid-19 pandemic. Thus, the purpose of this study is to develop android-based teaching materials for massage sports learning that are by the needs of the student context and technological advances.

\section{Materials and Methods}

\subsection{Research Method}

The study was a research and development (R \& D) method using Borg and Gall model and ADDIE model. The two models were adopted into three main steps, namely, namely 1) preliminary study, product trial, and dissemination. Procedural development steps followed their steps, starting from initial analysis to product effectiveness during implementation.

\subsection{Participants}

The research was carried out from July 2019 to May 2021. The participant was taken randomly to each University. Three universities in East Java were involved in this research. There were 200 students as research subjects have used and provided their feedback on the products we developed. Students from three universities in East Java were divided into three groups consisting of 20 students who participated in the initial trial, 100 students involved in the main field trial, and 80 students were involved in product implementation. The product implementation process was carried out using the true experimental control group method with 40 students in the experimental group and 40 students in the control group. The participant was taken randomly to each University. Participants involved in the research were divided into 3 parts, namely:

\subsection{Process of Collecting Data}

The process of collecting data used several ways, namely:

a Observation. The observation guide was developed to describe the current learning environment. It was done in a preliminary study to get the problems information of material in massage sports learning. It was done to get the needs analysis data related to the sports massage learning material.

b Document. It was taken from the syllabus and material which has been used in sports massage learning.

c Interview. Interview guidelines were prepared to determine the level of student satisfaction with the developed application. It was done to get the student's and colleagues' perceptions about the product in the product trial process both small and large trials. Students who were involved in product trials in small and large groups at the end of the lesson were interviewed by researchers. $85 \%$ of the participants in this stage were taken to be interviewed.

d Questionnaire. The questionnaire was developed with the indicators mentioned in the questionnaire section to determine the quality of the product developed from the student's perspective. It was distributed to students and colleagues to obtain the needs of teaching materials in massage sports learning related to technology. In addition, the questionnaire was also used to assess the product being tested in small and large groups. The questionnaire was designed using a closed questionnaire type and participants had to choose the answers that had been provided related to the questions. The questionnaire used a Likert scale with five answer choices.

Table 1. Participant Demographic

\begin{tabular}{|c|c|c|c|}
\hline Criteria & small group trial & large group trial & effectiveness test \\
\hline \multirow{2}{*}{ Ages $18-25$} & $18-21=12$ students & $18-21=62$ students & $18-21=40$ students \\
& $22-25=8$ students & $\mathrm{2}-25=38$ students & $\mathrm{M}=40$ students \\
\hline \multirow{2}{*}{ Gender } & $\mathrm{M}=12$ & $\mathrm{~F}=58$ & $\mathrm{~F}=40$ \\
\hline Students in Sports & $\mathrm{F}=8$ & 100 & 80 \\
Program Study & 20 & & \multirow{2}{*}{} \\
\hline
\end{tabular}



The validity of the instrument used the judgment expert consisting of technology experts, curriculum experts, and experts in physical activity and sports. While the reliability of questionnaire items used Cronbach's Alpha value. It is $>0.70$, the result of the test $0.76>0.70$ and the questionnaire was reliable. 4) The test was used to get the improvement of students' achievement in massage learning using the android application. 5) Document was taken from syllabus and material which were used in the universities.

\subsection{Procedure}

The research began with the collection of initial data consisting of a literature review, the results of current learning observations and a need analysis questionnaire at several universities. Initial data was used to design a mobile learning application model that would be developed, several devices such as storyboards and other materials (text, images, and videos) were collected and then assembled into a developed product. The product was packaged in the form of *.apk which was installed on a smartphone device. It was produced and operated on a smartphone, the product was tested on a limited basis by the researcher and development team, revising the product if necessary. The finished product was validated by experts to get the content validity of the developed product. The experts involved include learning technology experts, massage sports material experts, and teaching and learning experts. After the validation process was complete, the next product was in an initial trial with 20 research subjects to determine their satisfaction with the product. After getting the results from the initial trial, the product was then continued in the main field trial with 100 subjects at several universities in Indonesia. The result of the feedback on field trials was used to revise the product until it was implemented. Product implementation was carried out using the true experimental control group method at three universities with a total of 80 subjects. The results of this implementation showed the level of student satisfaction with the product and the level of effectiveness of the product in helping students achieve better learning outcomes.

The procedure of the study was adopted from Borg and Gall model with the ADDIE model. It was described in the following picture.
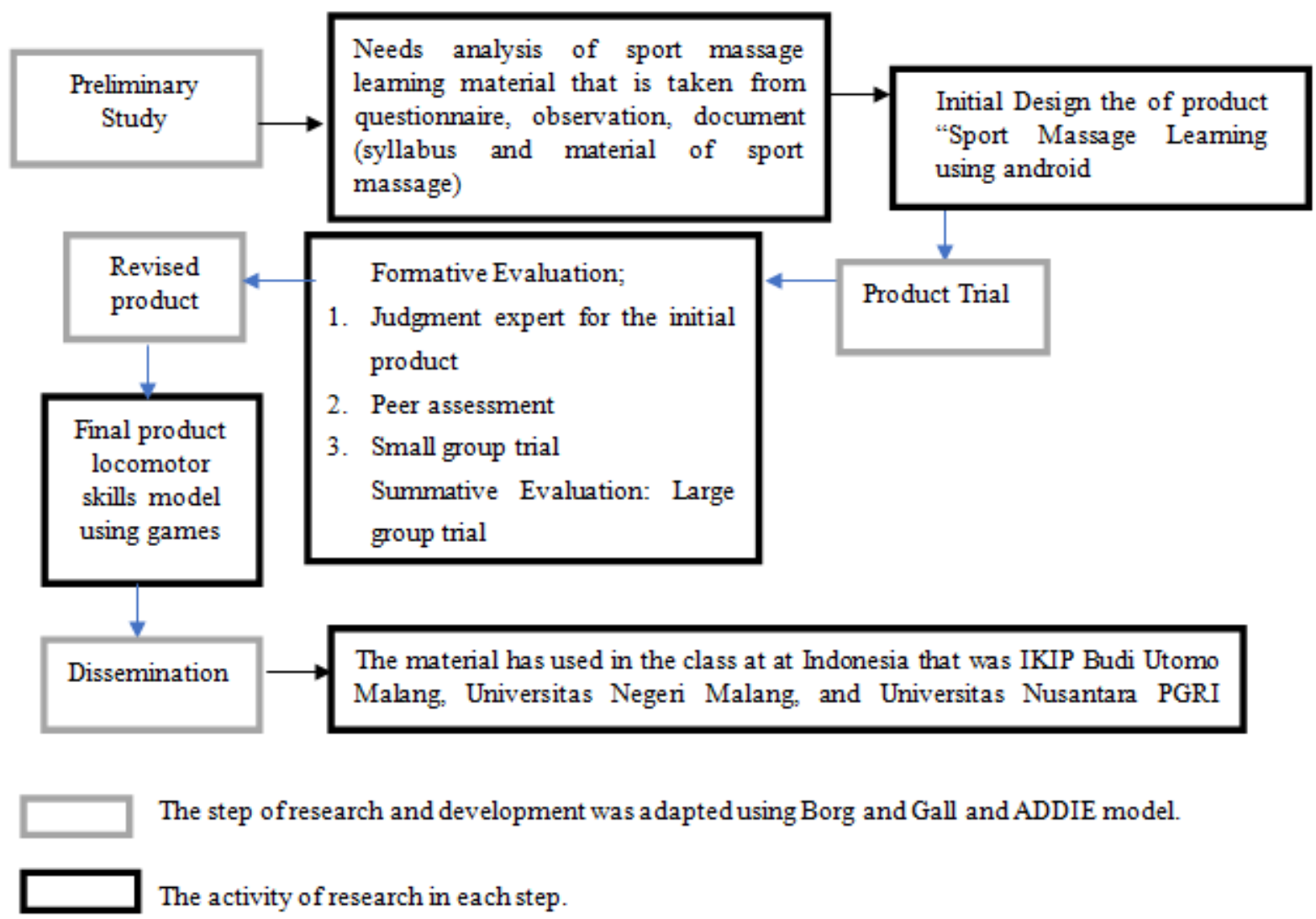

Picture 1. The procedure of Research and Development (Researcher framework of the study: adapted from Borg and Gall and ADDIE model) 


\section{Result}

The results of the needs analysis concluded that a) the sports massage learning process still used book media and LCD, requires an electrical plug, requires a laptop, requires a screen for delivering sports massage material, b) there was limited time in sports massage learning so that massage learning sports were not optimal, c) the material presented in sports massage learning only refers to a few learning resources. It was from lectures and textbooks which were sometimes difficult to find by students, d) the renewal of learning media using technology was needed because textbooks that had a visualization of basic sports massage techniques were still limited. It gave the wrong perception of sports massage technique movements if students interpret the description of sports massage techniques incorrectly. However, if there was a video simulation of sports massage technique movements, it would further clarify the visualization of sports massage technique movements to be clearer and more precise. These findings were the reason for the need for the development of a sports massage model that was by the needs and technological developments at present.

There were several important conclusions in the needs analysis that related to the development of android-based massage sports teaching materials.

1. The data showed that $61.70 \%$ of sports massage lessons were taught a week and $38.30 \%$ of sports massage lessons were taught twice a week. Thus, students' understanding of sports massage material was quite low. Students had difficulty in learning the material being taught without any learning media.

2. The data showed that students opened learning applications as much as $6.38 \%$, students opened Facebook applications as much as 40.43 and students opened Instagram applications as much as $23.40 \%$.

3. The data showed that $38.30 \%$ of students chose Android application media, $23.40 \%$ of students chose printed books and $14.89 \%$ of students chose to learn VCD. This means that students had an enthusiasm for android-based media that were adapted to the progress of the times and technological developments in the current era. This media was considered to be used for learning anytime and anywhere without being bound by space and time.

4. The data showed that $97.87 \%$ of students already had an android phone. While $2.13 \%$ did not have it so that if the sports massage learning media was packaged in the form of an android-based application, there were no obstacles for students to access it.

5. Students who agreed that sports massage learning was designed using an android application were $87.23 \%$.

The following was a picture of the "MassageSmartClick" application that has been designed on a mobile phone. This application had several menus, namely:

1. The splash screen. The following was a splash screen of the Android App product after a revision;

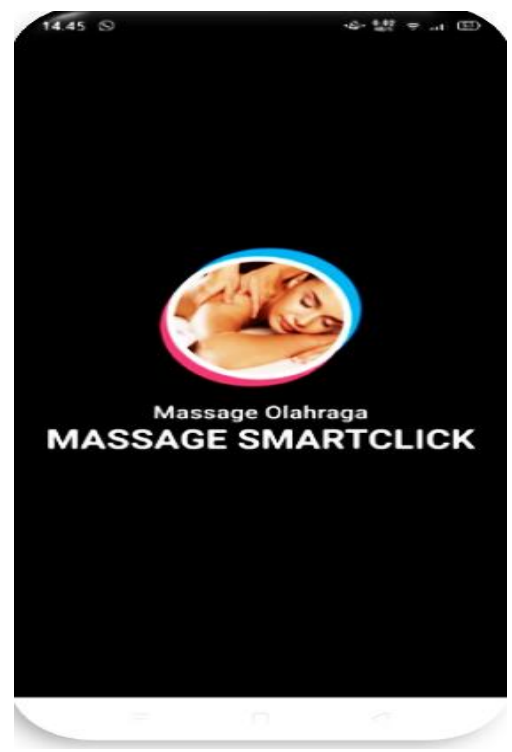

Picture 2. Splash Screen "Massage SmartClick"

Picture 2 was divided into four displays, namely: 1) the name of the application "MassageSmartClick", 2) bringing up the Welcome Word, 3) bringing up information on the homepage which contained what competencies was obtained after using the application, 4) bringing up information Attention that was important to read before starting to open the application.

2. The menu screen.

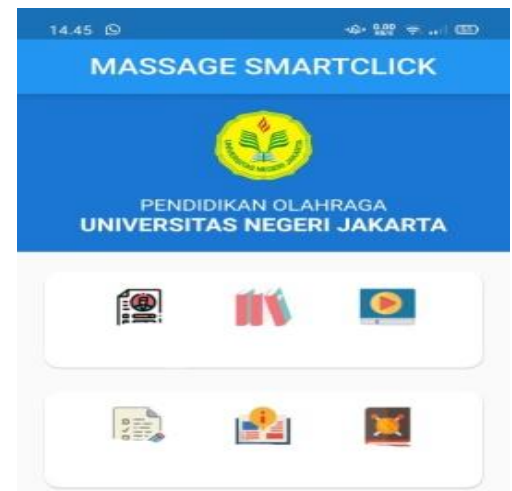

Picture 3. Menu Screen "Massage SmartClick"

Picture 3 is the main menu that contained icons that had been designed to make it easier for students to choose what submenu they wanted and would choose next. 
3. The Competency sub-menu

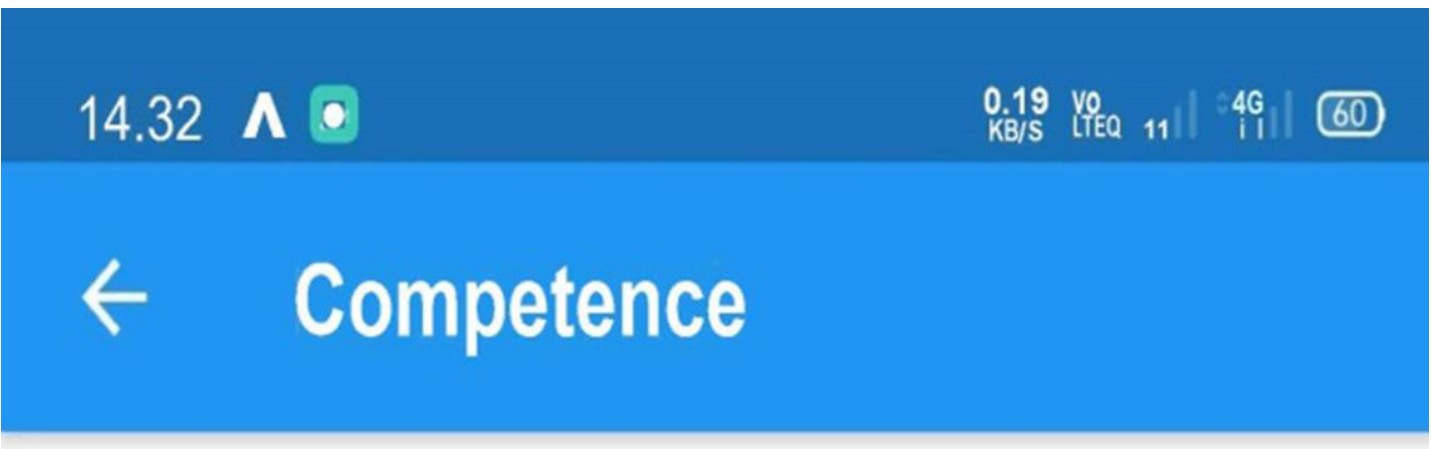

\section{LEARNING PLAN}

$\begin{array}{ll}\text { PROGRAM STUDY } & \text { Physical Education Health and Recreation } \\ \text { SUBJECT } & \text { Massage Olahraga } \\ \text { CODE } & \text { PJKR 030 } \\ \text { CREDIT } & 2 \text { Credits } \\ \text { SEMESTER } & \text { Odd } i \text { V (Five) } \\ \text { PREREQUISITE SUBJECT } & \text { Sport Anatomy and Physiology } \\ \text { LECTURE } & \text { Body Ardianzah Efendy,MPd } \\ \text { LEARNING OUTCOME } & \text { Analysing the concepts and priciples of massage and proficient in performing sports massage } \\ & \text { techniques properly and correctly }\end{array}$

Picture 4. Competency sub-menu Screen "Massage SmartClick"

Picture 4 contained the semester learning plan which contained what students must achieve in sports massage lectures.

4. The Materials sub-menu.

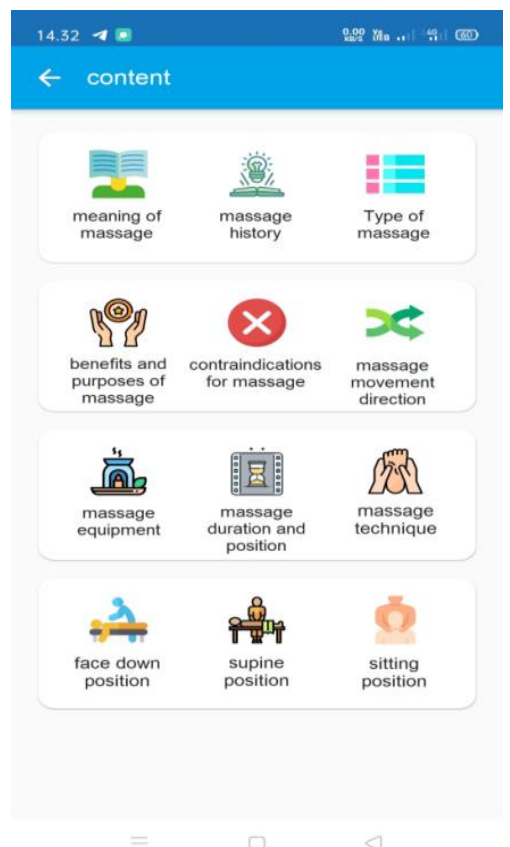

Picture 5. Material Sub-menu Screen "Massage SmartClick"

Picture 5 contained sports massage material and sports massage techniques that had been arranged in such a way that it was easy for students to understand the contents of the entire material
5. The illustration sub-menu.

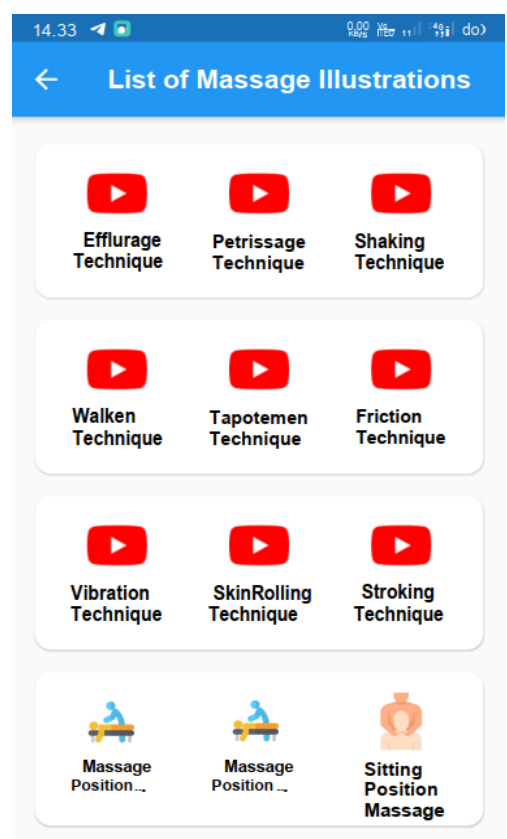

Picture 6. Illustration Sub-menu Screen "Massage SmartClick"

Figure 6 contained videos of sports massage technique movements so that it was easier for students to understand good and correct sports massage techniques. 


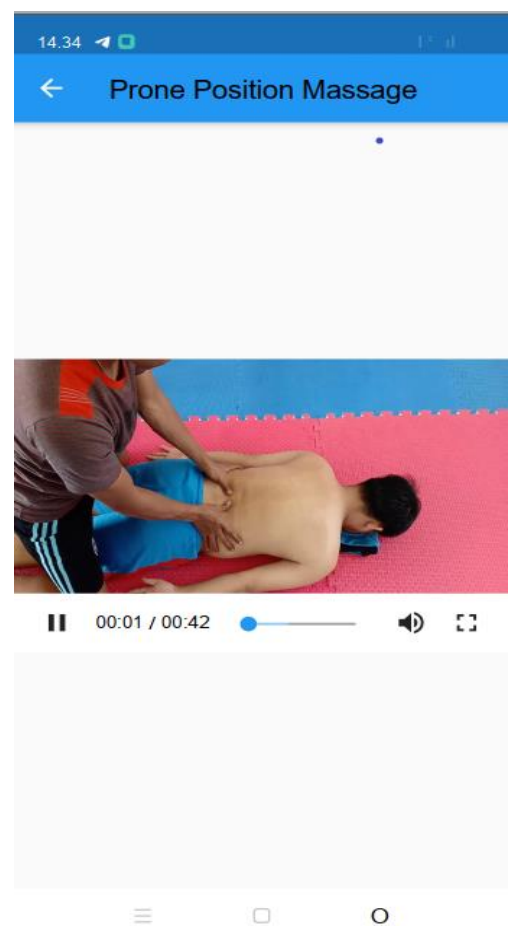

Picture 7. Example Video of Massage Motion in "Massage SmartClick"

6. The evaluation sub-menu.

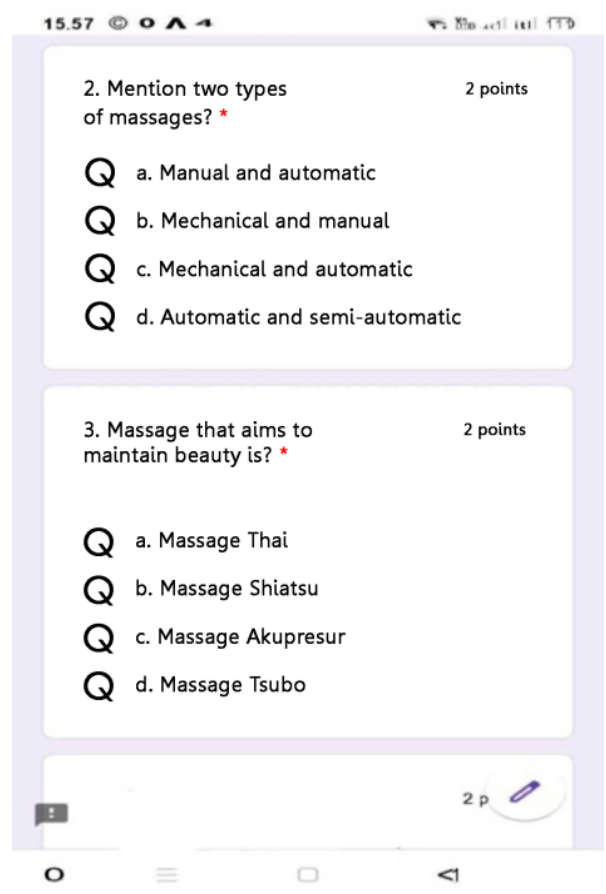

Picture 8. Evaluation Sub-menu "Massage SmartClick

Picture 8 contained questions about all the material presented, the questions were with multiple choice answers and students can see directly the scores obtained after answering these questions. The goal was to find out how far students were in mastering the material presented.
7. Information on the application developer who had a role in designing and supporting the creation of the MassageSmartClick Android application.
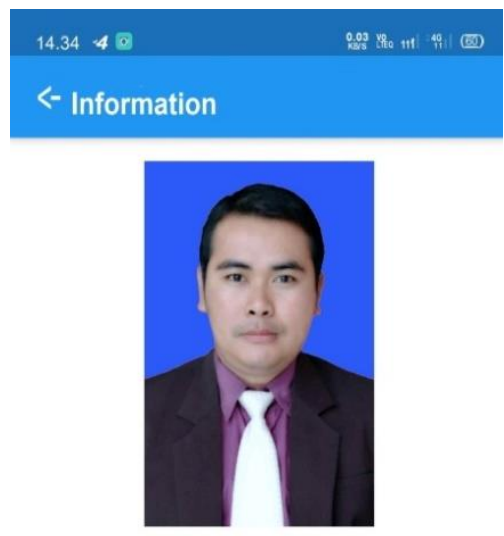

Designer

Picture 9. Information sub-menu "Massage SmartClick

Picture 9 presents the three product designers. The main designer as the actor who carried out research activities was Boby Ardianzah. The development of this product is assisted by research supervisors Prof. Dr Achmad Sofyan Hanif and Dr Imam Sulaiman.

The test results in the large group test also showed that students had a significant improvement in massage learning outcomes after using the new teaching material model. The results of the Independent Samples Test obtained the value of $t=12,588$ and the value of Sig. (2-tailed) or p-value $=0.000<0.05$ or Ho was rejected. So, it can be concluded that the android-based teaching materials model had a significant influence on mastery of massage learning.

\section{Discussion}

The android application product that had been developed was designed very clearly because it had several menus that made it easier for students to use the application. Some of the menus displayed were 1) splash screen "Massage SmartClick" displayed the first-page screen in the application, 2) menu screen displayed the start page for menus in the application, 3) competency sub-menu screen displayed information on learning activities in one semester, 4) screen sub-menu material contained various massage sports materials that had been designed according to the student need, 5) illustration sub-menu screen and example video of massage motion included examples of massage sports technique movements that made it easier for students to understand all movements, 6) evaluation sub-menu described information about student learning outcomes assessment, and 7) information sub-menu related to product designers.

The development product in the form of an 
Android-based sports massage learning application had provided complete data. Many applications were developed through the basic android base. Web3D was a concept of interactive web content in three-dimensional (3D) form assisted by WebGL (Web-based Graphics Library) as an engine and was a Platform Application Programming Interfaces (API) 3D graphics library that allowed internet browsers to create 3D scenes [21]. Besides, the teachers can design material using the android application as the basis of designing. The coach can use an android-based design in preparing the material to train the sensory-motor [22],[23]. The product presented the history of the development of sports massage, the purposes and benefits of sports massage, indications and contraindications of sports massage, requirements in sports massage, principles of sports massage, basic sports massage techniques along with examples of basic sports massage techniques. Sports massage material that was packaged in applications and textbooks was arranged systematically, from easy to difficult. Technology had also made learning activities easier today in the era of the Covid-19 pandemic [24]. With this application, students can still understand the basic techniques of massage movements in sports.

The product was equipped with an application manual which was integrated into one with the "Learn Easy Sports Massage" textbook which was designed as attractive as possible so that readers can easily understand and practice sports massage techniques. As we know that android-based digital books can trigger an interactive and independent learning environment between students and students and teachers because students' enthusiasm for learning tended to be high [25]. So that the learning targets can be delivered completely. Limitations in further research can be developed. This sports massage learning application can be installed by all users who had an android hand tree in the play store by providing a capacity slot of $500 \mathrm{Mb}$. The location for taking sports massage technique videos was in the multipurpose building of IKIP Budi Utomo Malang, and the demonstrations and equipment used were simple to make it easier for students to practice in the field.

In addition to having several advantages, the development of an Android-based sports massage model in this sports massage course also had several limitations or shortcomings. However, after several improvements and revisions had been made, it was expected to minimize the shortcomings contained in this model product. The results of the presentation of massage learning videos can be complemented by physiological and psychological effects as evidence of clinical trials on the effects of mastering basic massage techniques [26]. Here were some disadvantages of the "MasaseSmartClick application:

a The "MasaseSmartClick" application product that had been made was still very simple both in terms of the overall design appearance. b Application products can only be installed and opened on smartphones with Android OS

c The application capacity still cannot be reduced because it can reduce the quality of the illustration video so that the size was still above $300 \mathrm{Mb}$.

\section{Conclusion}

"MassageSmartClick" was a product of Android-based teaching materials that can be accessed using a mobile phone anywhere and anytime. This product had the feasibility and effectiveness in improving massage learning in the classroom and outside the classroom. From the findings of the product trial, it was concluded that students also had high learning enthusiasm. The display on each menu was clear and attractive to students. This also had an impact on the mastery of basic massage techniques and the achievement of learning outcomes.

In addition, the results of the study also had implications for the learning process which became easier and faster because students can learn anytime, anywhere without being bound by space and time, so that learning objectives can be achieved. The results of expert validation, field testing and model effectiveness testing were suggested that lecturers who support sports massage courses applied the product of this development model as a learning medium in the process of lecturing sports massage courses on campus.

However, the development of this product was still limited to one course and the videos used during the research process were also uploaded on YouTube. Thus, this research can still be developed by designing videos of students' massage learning outcomes as an example of the basic techniques of massage movements. This can be a form of appreciation for groups of students in doing assignments. The android-based sports massage model needed to be followed up by increasing the innovation of its use in various campuses so that the interaction process between lecturers and students can be more meaningful.

\section{REFERENCES}

[1] K. Purcell, A. Heaps, J. Buchannan, and L. Friedrich, "How Teachers Are Using Technology at Home and in Their Classrooms | Pew Research Center's Internet \& American Life Project," Pew Res. Cent., p. 108, 2013.

[2] H. Seppala P. A, "[JOURNAL BI] Mobile learning in teacher training," vol. 19, no. 3, p. 330, 2003.

[3] J. Cheon, S. Lee, S. M. Crooks, and J. Song, "An investigation of mobile learning readiness in higher education based on the theory of planned behavior," Comput. Educ., vol. 59, no. 3, pp. 1054-1064, 2012, doi: 10.1016/j.compedu.2012.04.015.

[4] A. Kukulska-Hulme, "Will mobile learning change language 
learning?," ReCALL, vol. 21, no. 2, pp. 157-165, 2009, doi: $10.1017 /$ S0958344009000202.

[5] Q. F. Yang, G. J. Hwang, and H. Y. Sung, "Trends and research issues of mobile learning studies in physical education: a review of academic journal publications," Interact. Learn. Environ., vol. 28, no. 4, pp. 419-437, 2020, doi: 10.1080/10494820.2018.1533478.

[6] D. Frohberg, C. Göth, and G. Schwabe, "Mobile Learning projects - a critical analysis of the state of the art: Original article," J. Comput. Assist. Learn., vol. 25, no. 4, pp. 307331, 2009, doi: 10.1111/j.1365-2729.2009.00315.x.

[7] K. Ciampa, "Learning in a mobile age: An investigation of student motivation," J. Comput. Assist. Learn., vol. 30, no. 1, pp. 82-96, 2014, doi: 10.1111/jcal.12036.

[8] M. Sailer, J. Murböck, and F. Fischer, "Digital learning in schools: What does it take beyond digital technology?," Teach. Teach. Educ., vol. 103, p. 103346, Jul. 2021, doi: 10.1016/j.tate.2021.103346.

[9] H. Crompton and C. Sykora, "Developing instructional technology standards for educators: A design-based research study," Comput. Educ. Open, vol. 2, p. 100044, 2021, doi: 10.1016/j.caeo.2021.100044.

[10] A. Subic, F. K. Fuss, F. Alam, and P. Clifton, "The Impact of Technology on Sport IV," Procedia Eng., vol. 13, p. 3, 2011, doi: 10.1016/j.proeng.2011.05.042.

[11] C. Xie and X. Xiao, Traceability of agricultural product quality and safety based on blockchain - taking fresh e-commerce as an example, vol. 1244 AISC, no. Atci. 2021.

[12] A. D. Olofsson, G. Fransson, and J. O. Lindberg, “A study of the use of digital technology and its conditions with a view to understanding what 'adequate digital competence' may mean in a national policy initiative," Educ. Stud., vol. 46, no. 6, pp. 727-743, Nov. 2020, doi: $10.1080 / 03055698.2019 .1651694$.

[13] V. Cho, K. C. Mansfield, and J. Claughton, "The past and future technology in classroom management and school discipline: A systematic review," Teach. Teach. Educ., vol. 90, p. 103037, Apr. 2020, doi: 10.1016/j.tate.2020.103037.

[14] A. Kos, Y. Wei, S. Tomažič, and A. Umek, "The role of science and technology in sport," in Procedia Computer Science, Jan. 2018, vol. 129, pp. 489-495, doi: 10.1016/j.procs.2018.03.029.

[15] F. Zioti, G. Clemente, R. De Paiva Gonçalves, M. Souza, A. Fassbinder, and I. M. Kawashita, "Understanding the use of mobile resources to enhance paralympic boccia teaching and learning for students with cerebral palsy," Proc. 12th Int. Conf. Mob. Learn. 2016, pp. 151-153, 2016.

[16] K. Sipilä, "Educational use of information and communications technology: Teachers' perspective," Technol. Pedagog. Educ., vol. 23, no. 2, pp. 225-241, 2014, doi: 10.1080/1475939X.2013.813407.

[17] N. Balacheff, S. Ludvigsen, T. De Jong, A. Lazonder, and S. Barnes, "Technology-enhanced learning: Principles and products," Technol. Learn. Princ. Prod., pp. 1-323, 2009, doi: 10.1007/978-1-4020-9827-7.

[18] M. G. Domingo and A. B. Garganté, "Exploring the use of educational technology in primary education: Teachers' perception of mobile technology learning impacts and applications' use in the classroom," Comput. Human Behav., vol. 56, pp. 21-28, Mar. 2016, doi: 10.1016/J.CHB.2015.11.023.

[19] V. Varea and G. González-Calvo, "Touchless classes and absent bodies: teaching physical education in times of Covid-19," Sport. Educ. Soc., vol. 0, no. 0, pp. 1-15, 2020, doi: 10.1080/13573322.2020.1791814.

[20] M. Kearney, S. Schuck, K. Burden, and P. Aubusson, "Viewing mobile learning from a pedagogical perspective," Res. Learn. Technol., vol. 20, no. 1, pp. 1-17, 2012, doi: 10.3402/rlt.v20i0/14406.

[21] Y. Rahmanto and R. Y. Utama, PENERAPAN TEKNOLOGI WEB3D BERBASIS ANDROID SEBAGAI MEDIA PEMBELAJARAN GERAKAN DASAR SILAT, vol. 9, no. 1. 2018.

[22] U. H. Refiater, J. Tangkudung, and Hernawan, "Development Model for Android-based Shot Put Orthodox Styles,” Int. J. Hum. Mov. Sport. Sci., vol. 8, no. 6A, pp. 5156, 2020, doi: 10.13189/saj.2020.080709.

[23] M. Al-Haliq, "The Effect of a Training Program Using Speed-Specific Strength Exercises on Sensory-Motor Perception in Learning Stroke Forehand Smash in Badminton Material for Students of the Hashemite University,” Int. J. Hum. Mov. Sport. Sci., vol. 8, no. 6, pp. 299-307, 2020, doi: 10.13189/saj.2020.080601.

[24] K. Iyengar, G. K. Upadhyaya, R. Vaishya, and V. Jain, "COVID-19 and applications of smartphone technology in the current pandemic," Diabetes Metab. Syndr. Clin. Res. Rev., vol. 14, no. 5, pp. 733-737, Sep. 2020, doi: 10.1016/J.DSX.2020.05.033.

[25] D. H. D. Hediansah, "Building Motivation and Improving Learning Outcomes with Android-Based Physics Books: Education 4.0.," Anatol. J. Educ., vol. 4, no. 2, pp. 1-10, Oct. 2019, Accessed: Jul. 18, 2021. [Online]. Available: https://doi.org/10.29333/aje.2019.421a.

[26] J. Brummitt, "The Role of Massage in Sports Performance and Rehabilitation: Current Evidence and Future Direction," N. Am. J. Sports Phys. Ther., vol. 3, no. 1, p. 7, Feb. 2008, Accessed: Jul. 18, 2021. [Online]. Available: /pmc/articles/PMC2953308/. 